Article

\title{
Laser Activated and Electroless Metalized Polyurethane Coatings Containing Copper(II) L-Tyrosine and Glass Microspheres
}

\author{
Piotr Rytlewski ${ }^{1, *}$, Bartłomiej Jagodziński ${ }^{1}$ (D) Rafał Malinowski ${ }^{2}{ }^{\circledR}$, Bogusław Budner ${ }^{3}$, \\ Krzysztof Moraczewski ${ }^{1}$, Agnieszka Wojciechowska ${ }^{4}\left(\mathbb{D}\right.$ and Piotr Augustyn ${ }^{1}$ \\ 1 Department of Materials Engineering, Kazimierz Wielki University, 85-064 Bydgoszcz, Poland; \\ bar.jag@ukw.edu.pl (B.J.); kmm@ukw.edu.pl (K.M.); augustyn@ukw.edu.pl (P.A.) \\ 2 Łukasiewicz Research Network-Institute for Engineering of Polymer Materials and Dyes, \\ 87-100 Toruń, Poland; rafal.malinowski@impib.lukasiewicz.gov.pl \\ 3 Institute of Optoelectronics, Military University of Technology, 00-908 Warsaw, Poland; \\ boguslaw_budner@interia.eu \\ 4 Faculty of Chemistry, Wroclaw University of Science and Technology, Wybrzeże Wyspiańskiego 27, \\ 50-370 Wroclaw, Poland; agnieszka.wojciechowska@pwr.edu.pl \\ * Correspondence: prytlewski@ukw.edu.pl
}

check for updates

Citation: Rytlewski, P.; Jagodziński, B.; Malinowski, R.; Budner, B.;

Moraczewski, K.; Wojciechowska, A.; Augustyn, P. Laser Activated and Electroless Metalized Polyurethane Coatings Containing Copper(II) L-Tyrosine and Glass Microspheres. Molecules 2021, 26, 5571. https:// doi.org/10.3390/molecules26185571

Academic Editor: Marek Bryjak

Received: 19 August 2021

Accepted: 9 September 2021

Published: 13 September 2021

Publisher's Note: MDPI stays neutral with regard to jurisdictional claims in published maps and institutional affiliations.

Copyright: (c) 2021 by the authors. Licensee MDPI, Basel, Switzerland. This article is an open access article distributed under the terms and conditions of the Creative Commons Attribution (CC BY) license (https:/ / creativecommons.org/licenses/by/ $4.0 /)$.
Abstract: Polyurethane coatings containing copper(II) L-tyrosine and glass microspheres were laser irradiated and underwent electroless metallization. Various sizes of glass microspheres were incorporated into the polyurethane coating matrix in order to examine their effects on surface activation and electroless metallization. The surface of the coatings was activated by using $\operatorname{ArF}$ excimer laser emitting ultraviolet radiation $(\lambda=193 \mathrm{~nm})$ using different number of laser pulses and their fluence. The effects of surface activation and metallization were evaluated mainly based on optical and scanning electron microcopies (SEM), energy-dispersive X-ray spectroscopy (EDX) and photoelectron spectroscopy (XPS). It was found that the presence of glass microspheres enabled the reduction in copper complex content, intensified the ablation process (higher cone-like structures created) and resulted in higher content of copper metallic seeds. On the other hand, the glass microspheres concentration, which was higher for lower size microspheres, was advantageous for obtaining a fully metallized layer.

Keywords: polymers; copper(II) L-tyrosine; glass microspheres; electroless metallization; lasers; surface activation

\section{Introduction}

The metallization of non-metallic materials, especially polymers, is an important industrial process crucial in the production of modern electronic or mechatronic devices [1-3]. The most common metallization techniques are physical vapor deposition (PVD), chemical vapor deposition CVD or chemical metallization (electroless metallization). Among these three techniques, electroless metallization is used on the largest industrial scale [4]. These methods are essentially classified as non-selective because all surface areas are metallized. In the case of selective metallization, only dedicated areas of the surface, e.g., conductive tracks are metalized, and this process commonly requires the application of surface masking. A relatively new and widely developed technique is electroless metallization of selectively activated surface areas with the use of laser radiation.

In the conventional electroless metallization method, the surface of the dielectric material is activated non-selectively by immersion in appropriate chemical solutions. Most often, it is a mixture of tin and palladium chlorides, sometimes preceded by chemical cleaning and etching of the surface of polymeric materials [5]. This process provides the socalled surface sensitization, which enables its activation in the next wet chemical treatment. 
Surface activation consists in adsorption of platinum or palladium ions, most often from a salt solution of these compounds. Only such a prepared surface is ready to be metallized in a solution containing metal ions, most often copper or nickel. These techniques require several chemical baths and do not provide the surface selectivity of metallization.

For the sake of these limitations, more ecological techniques of selective metallization with the use of laser radiation are currently developed. In one variation of these methods, the surface may be laser pre-activated and then activated and chemically metallized only in the area of laser irradiation [6,7]. In another variation of these methods, the surface is directly activated by laser radiation and then directly and electrolessly metallized $[8,9]$. The latter group of methods requires the prior incorporation of metallization precursors into the matrix of the polymer coating or the entire volume of polymer material. This technique is often referred to molded interconnect devices (MID) manufacturing, and it has the advantage in reducing surface preparation steps, while its disadvantage refers to the need of metallization precursors which need to be co-compounded with polymer materials [10,11].

These precursors can be organic and/or inorganic compounds of metals, especially copper in the case of selective copper plating. The most commonly used inorganic compounds are copper aluminum oxide [12], copper-chromium oxide [13], copper hydroxyl phosphate [14], whereas the effectiveness of organometallic compounds has been confirmed, e.g., palladium-acetate [15], copper acetate [16] and copper acetylacetonate [17,18]. The mechanism of laser activation is, on the one hand, ablation of the matrix and organic ligands when organometallic compounds are applied, and the reduction of these metal compounds to a metallic form on the other hand. Metal agglomerates formed locally on the surface under laser radiation constitute active sites for electroless metallization.

Various types of lasers are used in laser surface activation techniques, with preference to the relatively cheap semiconductor lasers having a wavelength of $1064 \mathrm{~nm}$. The range of this radiation corresponds to photons with energies of about $1.17 \mathrm{eV}$, which is significantly lower than the energy of chemical bonds in polymer materials. In that case, surface activation is purely thermal because only an increase in temperature enables the breaking of chemical bonds and ablation with the precipitation of metal agglomerates on the surface.

Currently, new directions in the development of laser activation techniques are focused on the search for new metallization precursors and on the selection of parameters for the laser irradiation process. This article meets these prospects because, on the one hand, a commercially unavailable copper complex in the form of copper(II) L-tyrosine is investigated, on the other hand, ultraviolet laser radiation is used, which is capable of breaking most chemical bonds in organic materials $(\lambda=193 \mathrm{~nm} / 6.4 \mathrm{eV})$. These studies in this area have already been published $[19,20]$. However, a significantly new element presented in this study is the use of glass microspheres, which made it possible to reduce the mass fraction of the copper complex in polymer matrix. This article shows the positive effect of microspheres and presents obtained results of metallization due to their sizes.

\section{Experimental}

\subsection{Materials}

The following materials were applied in this study:

- Substrate of polymer coatings, polycarbonate (PC), trade name: Xantar 19 UR (DSM Engineering Plastics, The Netherlands), with a melt flow rate MFR $=19.4 \mathrm{~g} / 10 \mathrm{~min}$ $\left(1.2 \mathrm{~kg}, 300{ }^{\circ} \mathrm{C}\right)$ and density of $1.20 \mathrm{~g} / \mathrm{cm}^{3}$;

- Matrix of polymer coatings, polyurethane resin type B4060 (Haering, Germany) with crosslinking agent B9031 (Haering, Germany);

- $\quad$ Additives for polymer coatings;

- Organometallic complex-copper(II) L-tyrosine ([Cu(L-tyr $\left.\left.)_{2}\right]_{n}\right)$, self-prepared;

- Glass microspheres (Dennert Poraver GmbH, Germany);

- Six-component metallization bath, type M-Copper 85 (MacDermid-Poland, Łysomice, Poland). 


\subsection{Preparation of Test Samples}

The test samples consisted of a polymer substrate and a polymer coating intended to be metallized. The polymer substrate consisted of polycarbonate plates obtained by injection molding, having a thickness of $1 \mathrm{~mm}$. A TRX 80 ECO 60 injection molding machine (Tederic Inc., Hangzhou, China) was used to produce the plates, with the temperatures of zones I, II, the head and the mold set to $285,285,285$ and $85^{\circ} \mathrm{C}$, respectively.

Polymer coatings were made of liquid polyurethane resins constituting the matrix of coatings to which copper(II) L-tyrosine (15 wt.\%) and glass microspheres (5 or $10 \mathrm{wt} . \%$ ) were introduced. Copper(II) L-tyrosine was obtained by chemical synthesis, the course of which was described in earlier article [21]. The structure of the studied complex is shown in Figure 1.

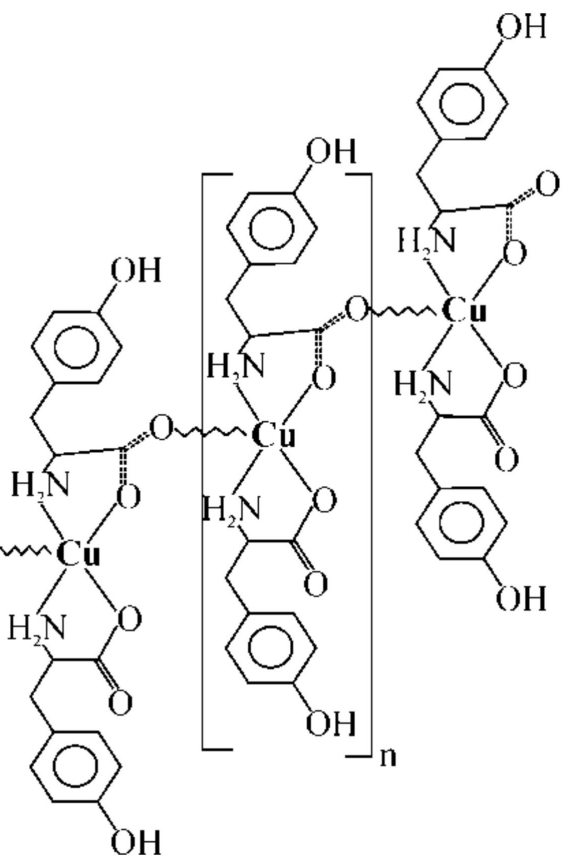

Figure 1. The schemes of $\left[\mathrm{Cu}(\mathrm{L}-\mathrm{tyr})_{2}\right]_{n}$.

The structure of the applied copper complexes was solved on the basis of the spectra determined by the KM4 X-ray diffractometer (KUMA Diffraction, UK) by numerical methods using the SHELXS-97 software. This complex was chosen because it was proved to be an effective metallization precursor, as demonstrated in recent work [19]. The obtained copper complex compound was dried at $40^{\circ} \mathrm{C}$ for $24 \mathrm{~h}$, crushed with a laboratory mortar, mixed with glass microspheres and polymer resin and finally evenly applied on polycarbonate plates.

Four types of glass microspheres, which differed in average size, were used for the tests. The selected physical properties of the microspheres used are listed in Table 1.

Table 1. Selected physical properties of the microspheres used.

\begin{tabular}{ccccc}
\hline Designation & $\begin{array}{c}\text { Size } \\
(\boldsymbol{\mu m})\end{array}$ & $\begin{array}{c}\text { Average Bulk } \\
\text { Density }\left(\mathbf{k g} / \mathbf{m}^{\mathbf{3}}\right)\end{array}$ & $\begin{array}{c}\text { Average Particle } \\
\text { Density }\left(\mathbf{k g} / \mathbf{m}^{\mathbf{3}}\right)\end{array}$ & $\begin{array}{c}\text { Crush Resistance } \\
\left(\mathbf{N} / \mathbf{m m}^{\mathbf{2}}\right)\end{array}$ \\
\hline$\Phi_{1}$ & od 40 do 60 & $530+/-70$ & $1400+/-300$ & - \\
$\Phi_{2}$ & od 100 do 150 & $400+/-60$ & $950+/-150$ & 2.8 \\
$\Phi_{3}$ & od 250 do 350 & $340+/-30$ & $700+/-80$ & 2.6 \\
$\Phi_{4}$ & od 500 do 700 & $270+/-30$ & $500+/-80$ & 2.0 \\
\hline
\end{tabular}

Each type of glass microspheres $\left(\Phi_{1}, \Phi_{2}, \Phi_{3}\right.$ or $\left.\Phi_{4}\right)$ was introduced into the coatings in the amount of 5 or $10 \mathrm{wt} . \%$ in order to verify their effect on the reduction of copper 
complexes occurring under the influence of laser radiation. It also seemed interesting to determine the potential influence of the size of these microspheres on the effects of electroless metallization.

\subsection{Laser-Induced Activation of Coatings}

The coatings on the PC substrate were irradiated with an ArF LPX PRO 305 excimer laser (Coherent Inc., Santa Clara, CA, USA), with a fluence of $100 \mathrm{~mJ} / \mathrm{cm}^{2}$ using 350 or 500 laser pulses. These irradiation parameters caused effective ablation and surface activation and were selected based on our previous study [20]. The applied laser fluence has a value higher than the ablation threshold energy of most polymer materials, which is about $20 \mathrm{~mJ} / \mathrm{cm}^{2}$. The fluence of laser pulses was determined with a FieldMax II TOP meter (Coherent Inc., Santa Clara, CA, USA). The samples were irradiated in air under ambient conditions.

The aim of laser irradiation was to activate the surface of polymer coatings, resulting in direct electroless metallization of the irradiated areas. The origins of such activation number in two alongside physicochemical processes taking place under the influence of laser radiation: laser ablation and reduction of copper from the complex structure into the metallic one so that the precipitated copper agglomerates covers the irradiated surface of the coating, thus rendering it activated.

\subsection{Electroless Metallization}

The metallization of the irradiated samples was carried out by using a six-component electroless copper plating bath type M-Copper 85 (with formaldehyde as a reducing agent. The metallization bath was prepared in accordance with the manufacturer's instruction, by mixing the ingredients in the correct order and quantity. The finished bath was poured into a glass vessel and heated to a temperature of about $46^{\circ} \mathrm{C}$, where the $\mathrm{pH}$ value was 12.8. The coatings on PC plates were metallized for $60 \mathrm{~min}$. During metallization, the bath was constantly aerated.

\subsection{Testing Techniques}

Scanning electron microscopy (SEM) was performed by using the SU8010 microscope (Hitachi, Japan). In order to obtain better imaging, the tested coatings were covered with a gold layer with a thickness of about $2 \mathrm{~nm}$ using a resistance evaporative sputtering machine (Cressington, UK). Images of the samples were recorded at an accelerating voltage of $15 \mathrm{kV}$ and a beam electron current of about $60 \mu \mathrm{A}$.

This microscope was also used for energy-dispersive X-ray spectroscopy (EDX). It was used to determine changes in the elemental composition of the coatings surface layer induced by laser irradiation. In order to obtain representative results of changes taking place in surface layer of the tested coatings, the surface area of $1.2 \times 0.9 \mathrm{~mm}$ of each tested coating was scanned with an electron beam. In the case of EDX experiments, the surface of the polymer coatings was not covered with gold in order to refrain from affecting registered changes in its chemical structure.

X-ray photoelectron spectroscopy (XPS) studies were carried out by using an R3000 spectrometer (VG Scienta, Sweden). The qualitative and quantitative analysis of copper in various oxidation states was performed based on vector analysis [22,23]. This fitting technique was described in our previous studies.

Tests of the adhesive strength of coatings/deposited copper layer were carried out by tearing off the glued stamp by using the Instron 3367 testing machine (Instron, USA). Measurement stamps with dimensions of $6.5 \times 20 \mathrm{~mm}$ and a special two-component adhesive Araldite 2011 (Huntsman, Switzerland), which is characterized by a very good ability to bond with metals and polymer materials, were used. 


\section{Results and Discussion}

The sizes of glass microspheres declared by the producer (see Table 1) were verified using optical microscopy (Figure 2).
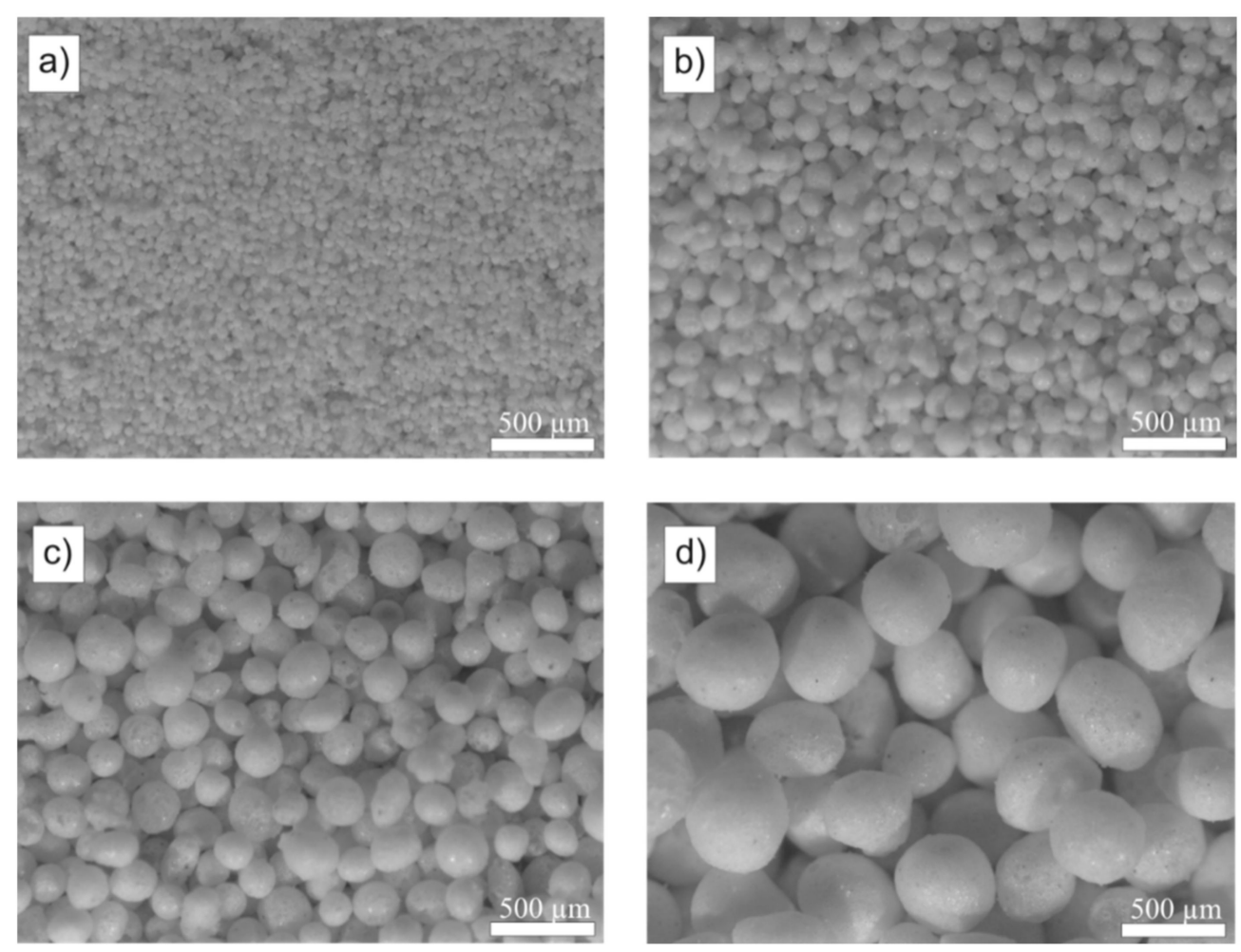

Figure 2. Optical images of glass microspheres: (a) $\Phi_{1}$, (b) $\Phi_{2}$, (c) $\Phi_{3}$ and (d) $\Phi_{4}$.

The manufacturer specifies a wide range of glass microspheres sizes. However, based on the microscopic analysis of representative groups of microspheres, it was found that their average size is close to the minimum values of the given ranges (Table 1). What is noteworthy is also a decrease in the average density of microspheres with an increase in their size, which indicates changes in the structure of the microspheres depending on their size.

Figures 3 and 4 show the results of electroless metallization of coatings with glass microspheres with the share of $5 \mathrm{wt} . \%$ or $10 \mathrm{wt} . \%$ and with four different grain sizes.

The use of microspheres allowed the electroless deposition of copper on laser-irradiated coatings, which contained only $15 \mathrm{wt} . \%$. of $\left[\mathrm{Cu}(\mathrm{L}-\mathrm{tyr})_{2}\right]_{\mathrm{n}}$. In the case of coatings containing no glass microspheres, the content of $15 \mathrm{wt} . \%$ of $\left[\mathrm{Cu}(\mathrm{L}-\mathrm{tyr})_{2}\right]_{\mathrm{n}}$ did not cause electroless metallization, regardless of the laser radiation parameters used. As presented in Figures 3 and 4 , the best metallization effects were obtained for coatings containing $\Phi_{1}$ glass microspheres. The larger the diameter of the glass microspheres, the less copper was deposited on the coatings as a result of electroless metallization. Better effects of electroless metallization were found in the case of coatings containing $10 \mathrm{wt} . \%$ of glass microspheres compared to those containing $5 \mathrm{wt} . \%$.

Coatings with $15 \mathrm{wt} . \%$ of $\left[\mathrm{Cu}(\mathrm{L}-\mathrm{tyr})_{2}\right]_{\mathrm{n}}$ and $10 \mathrm{wt} . \%$ of glass microspheres of different sizes $\left(\Phi_{1}, \Phi_{2}, \Phi_{3}\right.$ and $\left.\Phi_{4}\right)$ were selected for detailed analysis. These coatings were irradiated with the same number of laser pulses $(\mathrm{N}=500)$ and at the same fluence $\left(100 \mathrm{~mJ} / \mathrm{cm}^{2}\right)$ in order to determine the influence of microsphere sizes on the changes induced by laser radiation. As presented in Figure 5, laser ablation caused the uncovering of microspheres and precipitation of copper agglomerates on the coatings surface. 


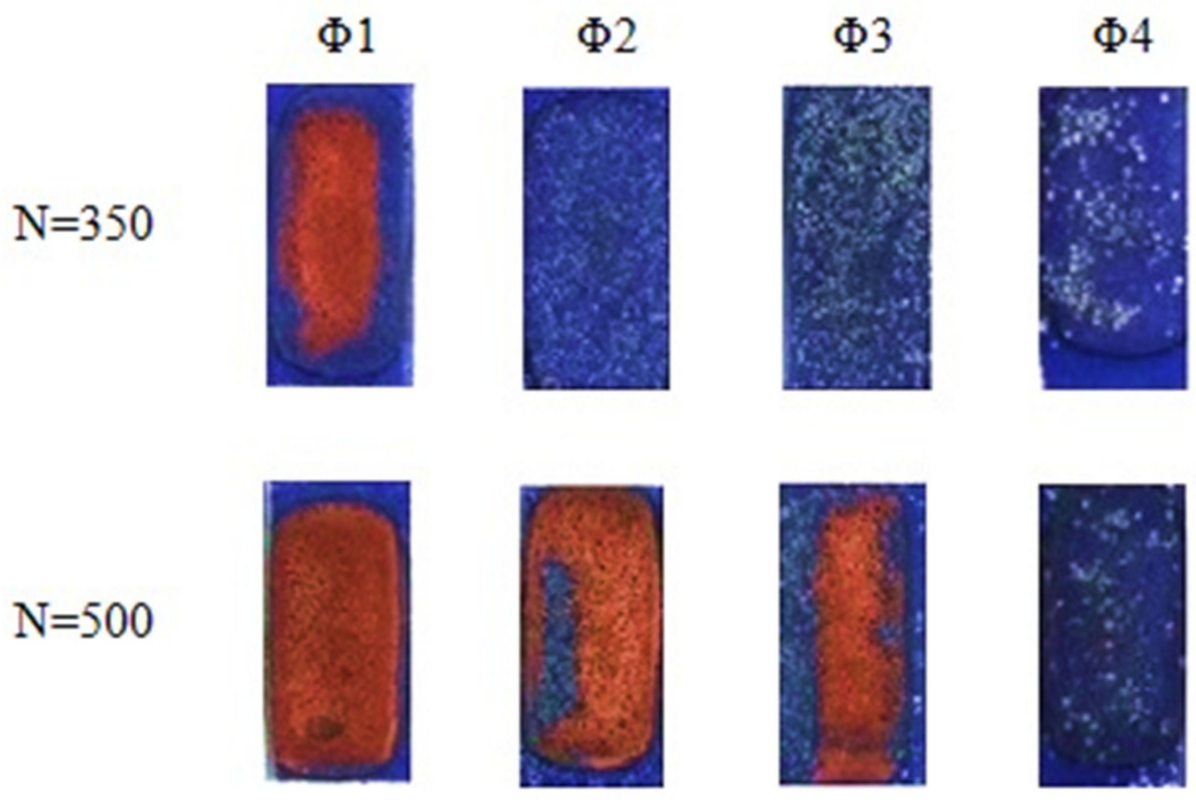

Figure 3. Coatings containing 15 wt. $\%$ of $\left[\mathrm{Cu}(\mathrm{L}-\mathrm{tyr})_{2}\right]_{\mathrm{n}}$ and $5 \mathrm{wt} . \%$ of glass microspheres $\Phi_{1}, \Phi_{2}, \Phi_{3}$ and $\Phi_{4}$, irradiated with 350 or 500 laser pulses $(\mathrm{N})$ with a fluence of $100 \mathrm{~mJ} / \mathrm{cm}^{2}$, after electroless metallization.

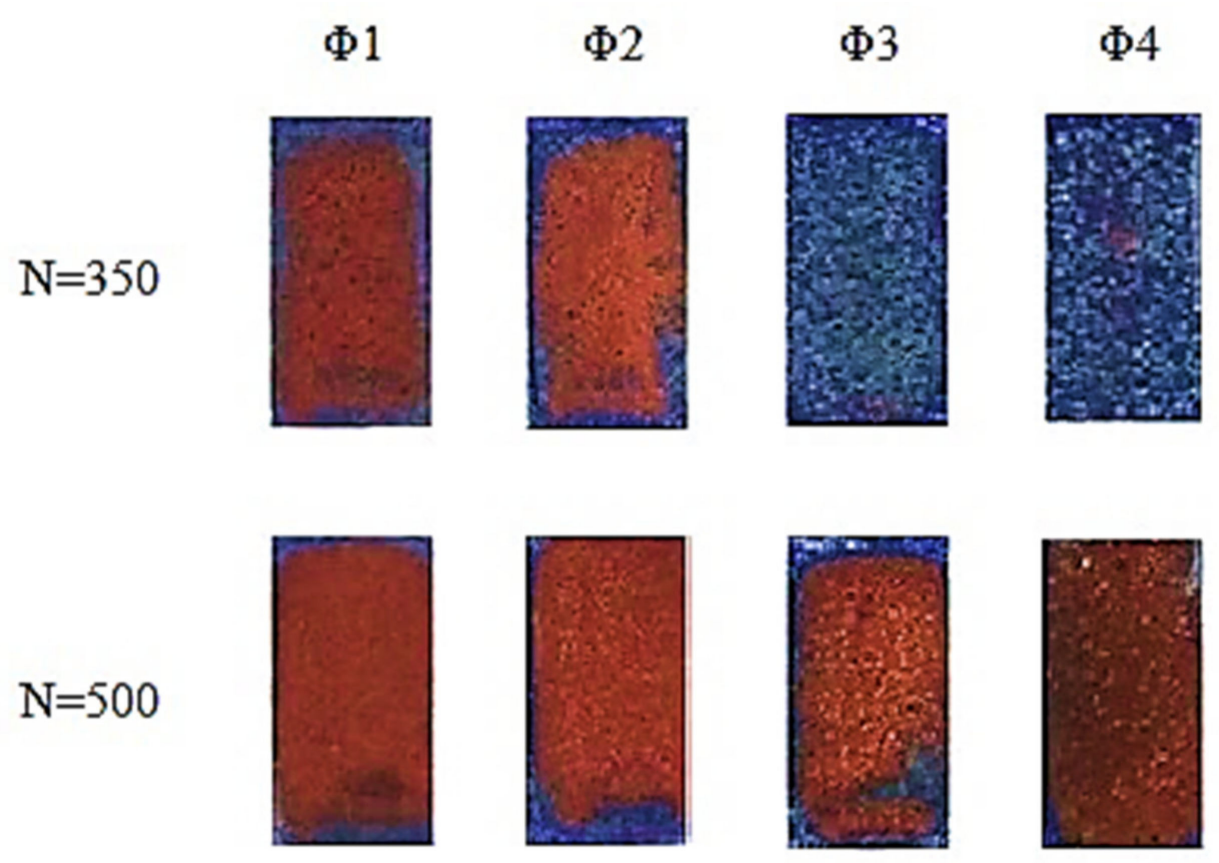

Figure 4. Coatings containing $15 \mathrm{wt} . \%$ of $\left[\mathrm{Cu}(\mathrm{L}-\mathrm{tyr})_{2}\right]_{\mathrm{n}}$ and $10 \mathrm{wt} . \%$ of glass microspheres $\Phi_{1}, \Phi_{2}, \Phi_{3}$ and $\Phi_{4}$, irradiated with 350 or 500 laser pulses $(\mathrm{N})$ with a fluence of $100 \mathrm{~mJ} / \mathrm{cm}^{2}$, after electroless metallization. 

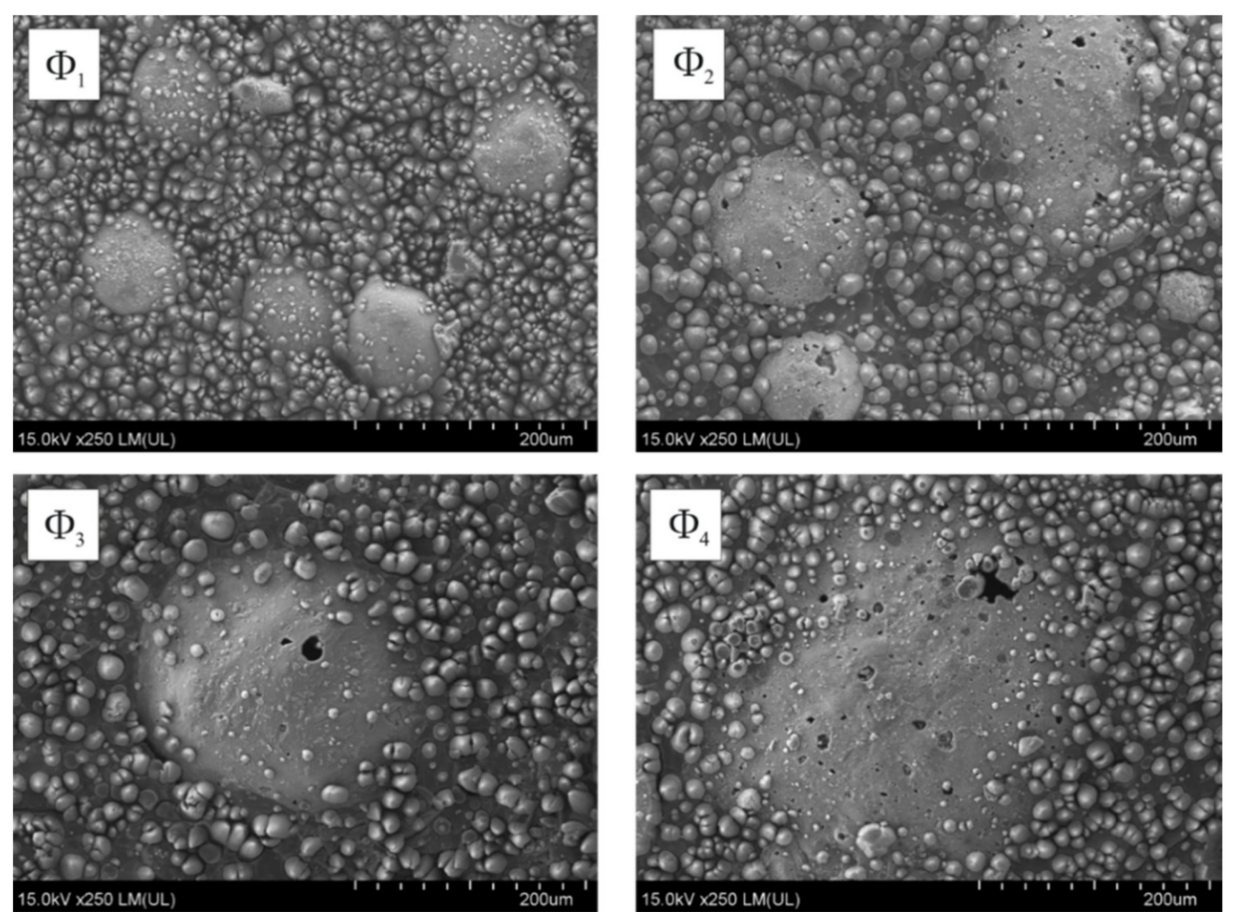

Figure 5. SEM images of laser irradiated $\left(N=500 ; E_{j}=100 \mathrm{~mJ} / \mathrm{cm}^{2}\right)$ coatings containing glass microspheres: $\Phi_{1}, \Phi_{2}, \Phi_{3}$ and $\Phi_{4}$.

Under the influence of laser radiation, numerous cones were formed in the coatings surface layer. These cones are clearly visible in SEM imaging of fractured samples taking the perspective view (Figure 6).
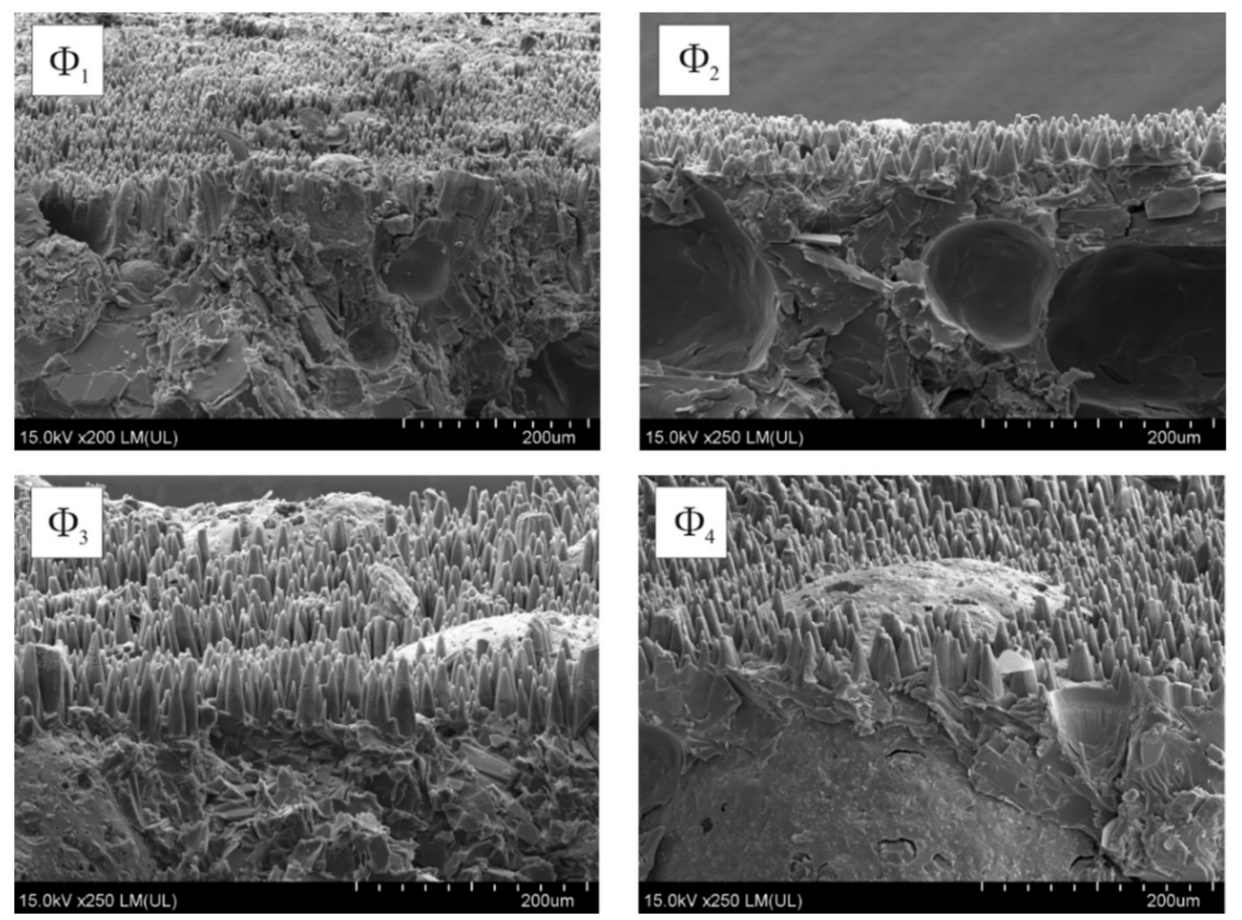

Figure 6. SEM images of laser irradiated $\left(N=500, E_{j}=100 \mathrm{~mJ} / \mathrm{cm}^{2}\right)$ coatings containing glass microspheres: $\Phi_{1}, \Phi_{2}, \Phi_{3}$ and $\Phi_{4}$. 
The formation of these cones can result from the significant difference in the ablation threshold for the copper and polymer matrix. The ablation threshold for copper $\left(2 \mathrm{~J} / \mathrm{cm}^{2}[24]\right)$ is significantly higher than the applied laser fluence. Therefore, laser irradiation can only cause the polymer matrix to be ablated, while precipitated copper will agglomerate and stay on the surface. Along with laser pulses, copper agglomerates form a local mask on the surface, thus protecting underneath created polymer cones. Although this mechanism was explained previously, one can perceive some interesting effects of varied size of microspheres.

The height of the cones on the surface of coatings irradiated with the same laser dose increased along with the size of the glass microspheres contained in these coatings. This finding can confirm the expectation that the glass filler as highly resistant to laser ablation will result in an increase in surface temperature and, thus, to a higher ablation rate.

It can be explained by the fact that glass filler gains much higher temperatures than the polymer matrix. In the case of polymer matrix, the maximum possible temperature can be estimated at about $400 \mathrm{C}$, which refers to the thermal degradation temperature. The successive laser pulses cannot increase this value. On the other hand, the ablation threshold for glass is about 50 times higher than for polymers. Therefore, radiation energy absorbed by glass filler can be converted only into heat without mechanical effects of ablation. The higher temperature which can be gained for glass than polymer also results from the following equation [25]:

$$
\Delta \mathrm{T}=\alpha F_{t h} / \rho c
$$

where $\alpha$ denotes absorption coefficient; $F_{t h}$ denotes ablation threshold; $\rho$ denotes material density; c denotes specific heat capacity.

With the higher temperature of glass microspheres, one can also expect higher precipitation rate of metallic copper.

Figure 7 shows the exposed areas of glass microspheres with diameters of $\Phi_{1}$ and $\Phi_{3}$ for which an EDX point analysis for the presence of copper was carried out.
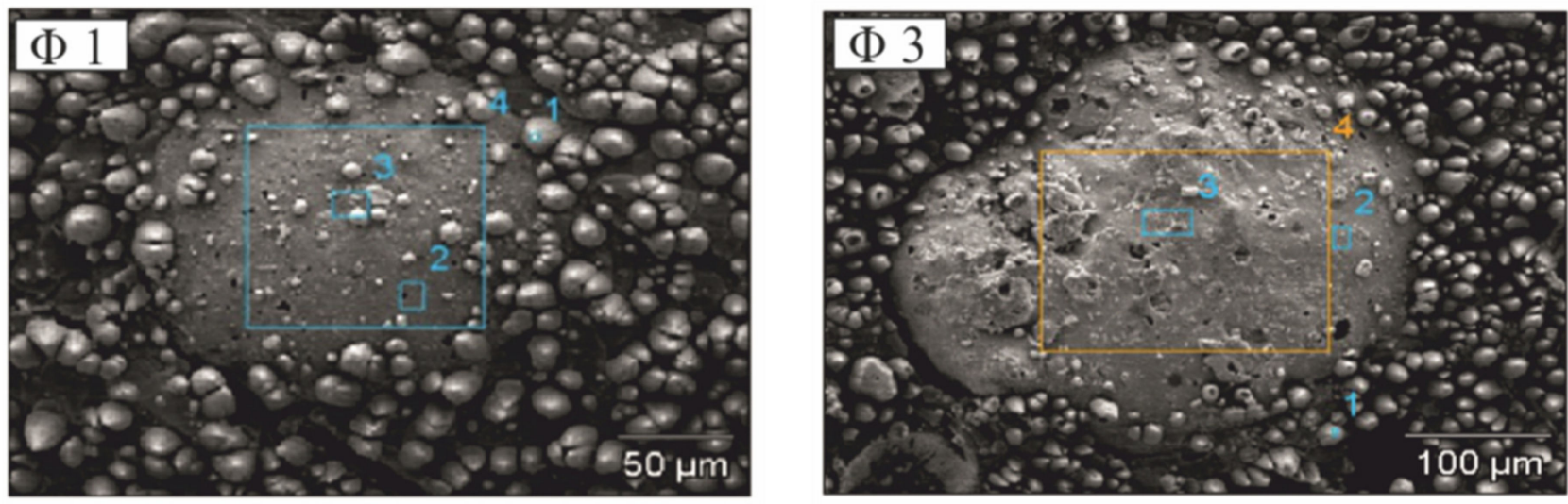

Figure 7. SEM images with rectangular areas on glass microspheres $\Phi 1, \Phi 3$ in coatings, where the amount of copper was examined by the EDX method.

The percentage of copper for the $\Phi_{1}$ microsphere area indicated in the Figure 7 was approximately 16 at $\%$, while for the $\Phi_{3}$ microsphere it was approximately $25 \mathrm{at} \%$. It is noticeable that with the increase in the size of the glass microspheres, due to irradiation with laser pulses, an increasing amount of copper is precipitated from copper L-tyrosine on the surface of the glass microspheres. This percentage of copper at the surface area of the glass microsphere itself is many times greater than the percentage of copper in the area of 1.2 per $0.9 \mathrm{~mm}$ of the coating, which was about $3 \mathrm{at} \%$, regardless of the size of the glass microspheres used. This means that the greatest concentration of copper is on the surface of the exposed glass microspheres than between them. 
The deposited copper layer structure reflected the same structure as shaped upon laser irradiation (Figure 8).
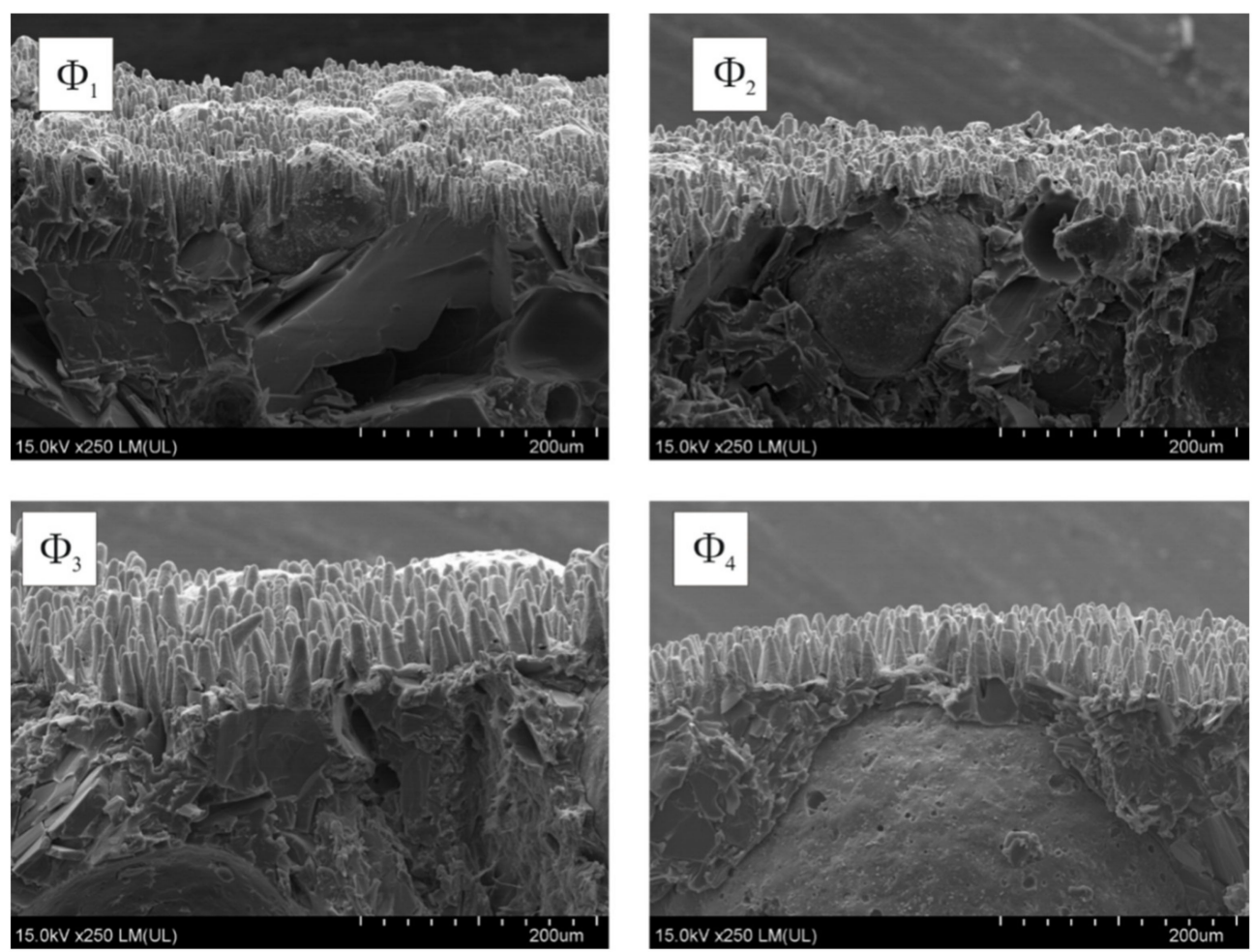

Figure 8. SEM images of laser irradiated $\left(\mathrm{N}=500 ; \mathrm{E}_{\mathrm{j}}=100 \mathrm{~mJ} / \mathrm{cm}^{2}\right)$ and metallized coatings containing glass microspheres: $\Phi_{1}, \Phi_{2}, \Phi_{3}$ and $\Phi_{4}$ (side view).

The height of the cones is of about several dozen micrometres; thus, the thickness of deposited copper can be estimated to be up to a few micrometres. However, simple electrical tests showed fine and good conductivity of about $7 \mathrm{~S} / \mathrm{cm}$; thus, the deposited copper layer can be considered continuous.

Based on the XPS measurements, a slight increase in the percentage of copper atoms in the coatings containing glass microspheres of higher size was found (Table 2). With XPS spectrophotometer applied in the tests, it is not possible to analyse the only exposed areas of the glass microspheres in order to confirm the results obtained from the EDX local analysis.

Table 2. Percentage (P) of copper, oxygen and carbon with an indication of the binding energy (E) of photoelectrons derived from these elements.

\begin{tabular}{ccccccc}
\hline \multirow{2}{*}{$\begin{array}{c}\text { Microasphers } \\
\text { Size }\end{array}$} & \multicolumn{3}{c}{$\mathbf{C u}$} & \multicolumn{2}{c}{$\mathbf{O}$} & \multicolumn{2}{c}{$\mathbf{C}$} \\
\cline { 2 - 7 } & $\mathbf{P}(\mathbf{a t} \%)$ & $\mathbf{E}_{\mathbf{B}}(\mathbf{e V})$ & $\mathbf{P}(\mathbf{a t} \%)$ & $\mathbf{E}_{\mathbf{B}}(\mathbf{e V})$ & $\mathbf{P}(\mathbf{a t} \%)$ & $\mathbf{E}_{\mathbf{B}}(\mathbf{e V})$ \\
\hline$\Phi_{1}$ & 2.7 & 932.66 & 18.8 & 532.56 & 78.5 & 284.96 \\
$\Phi_{2}$ & 3.2 & 932.62 & 20.8 & 532.37 & 76.1 & 284.87 \\
$\Phi_{3}$ & 3.6 & 932.62 & 19,7 & 532.62 & 76.7 & 285.22 \\
$\Phi_{4}$ & 3.7 & 932.56 & 19.4 & 532.51 & 76.9 & 285.12 \\
\hline
\end{tabular}

As observed from Table 2, with the greater size of microspheres, the copper content slightly increased. In the analysed surface layer with a thickness of several nanometers, the share of copper in the coatings containing glass microspheres was higher than in coatings without microspheres. In coatings containing $20 \mathrm{wt} . \%$ (without microspheres), irradiated at the same conditions $\left(\mathrm{N}=500 ; \mathrm{F}=100 \mathrm{~mJ} / \mathrm{cm}^{2}\right)$, the copper content was lower than 2 
at $\%$ [20]. Therefore, higher content of copper proves that glass microspheres affected the reactions conditions on the surface. This finding is consistent with the one concerning the height of the cones, which was discussed previously when referring to Equation (1).

Figure 9 shows photoelectron spectra with matching spectra, respectively, for each of the forms of copper, $\mathrm{Cu}(0) \mathrm{CuO}, \mathrm{Cu}_{2} \mathrm{O}$ and $\mathrm{Cu}(\mathrm{OH})_{2}$, whereas in Table 3 is the percentage for each of these copper forms.

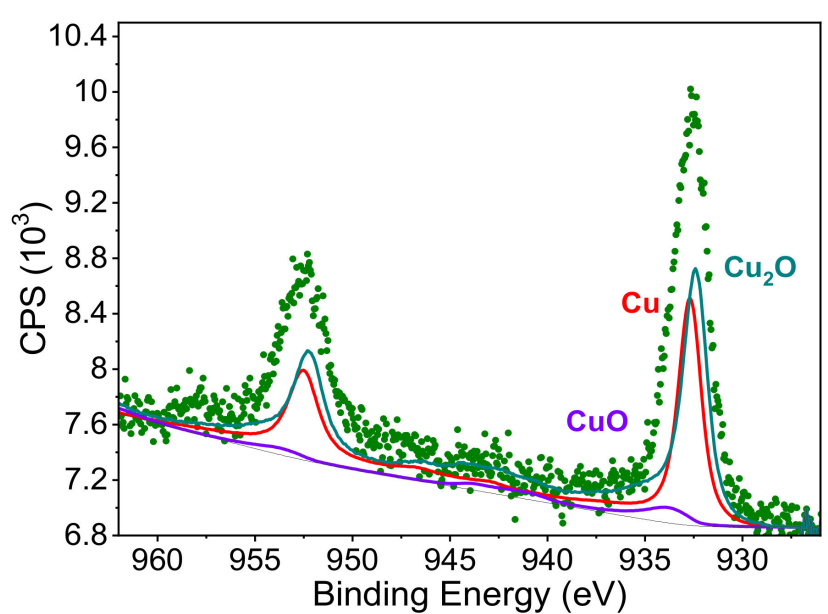

(a)

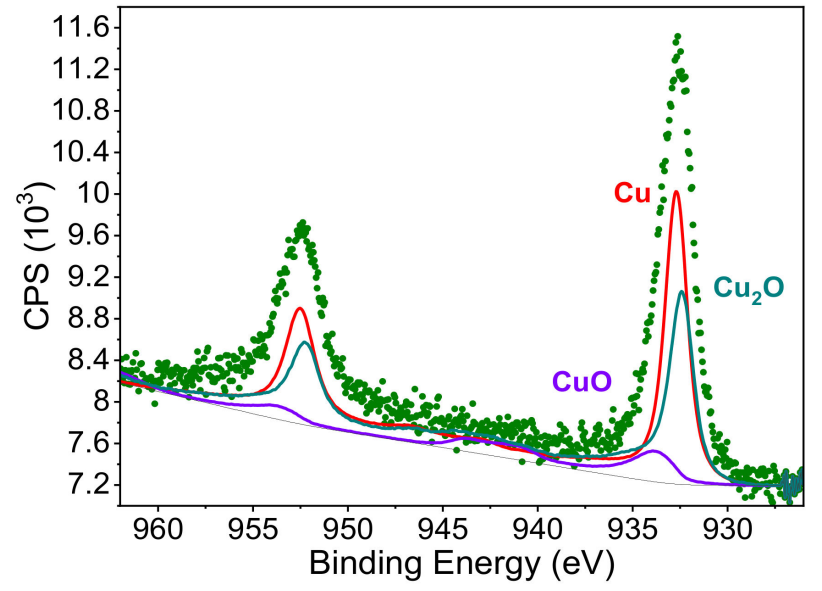

(c)

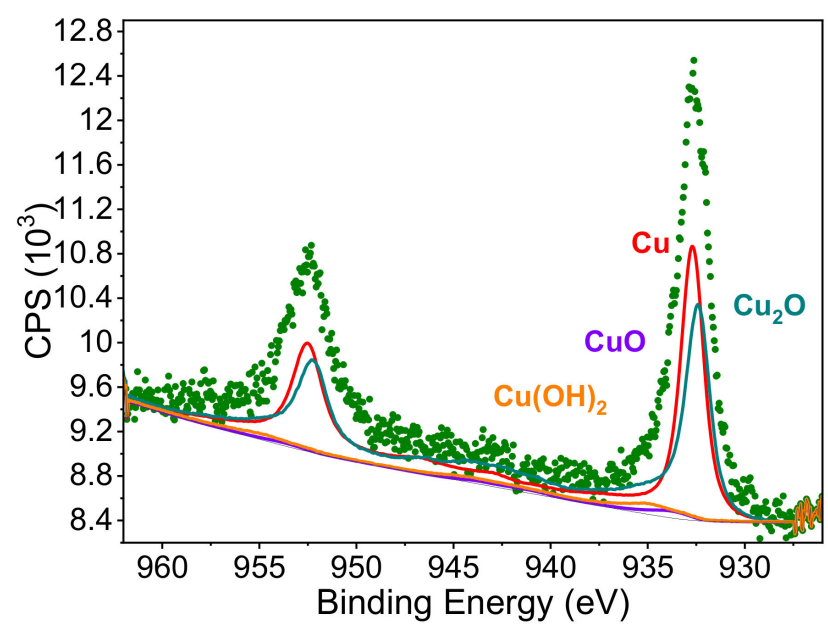

(b)

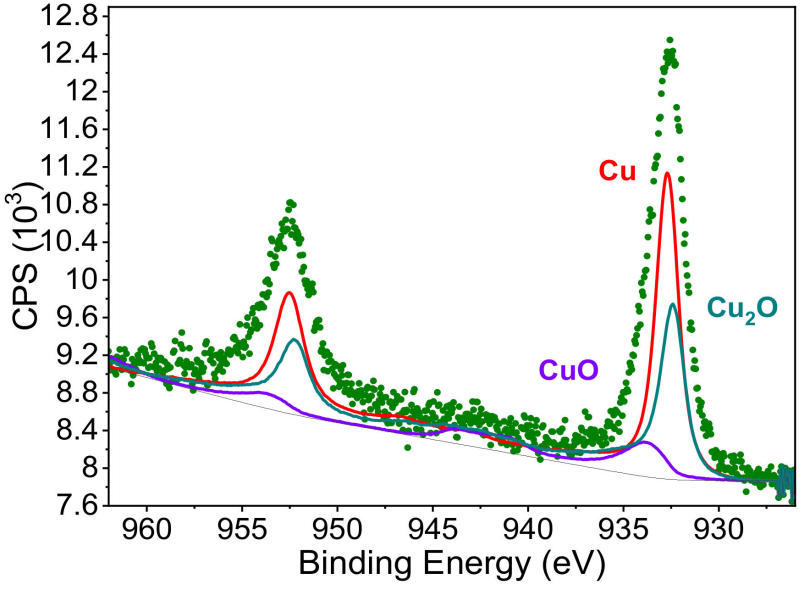

(d)

Figure 9. XPS spectra of laser irradiated $\left(\mathrm{N}=500 ; \mathrm{Ej}=100 \mathrm{~mJ} / \mathrm{cm}^{2}\right)$ of coatings containing microspheres: (a) $\Phi_{1},(\mathbf{b}) \Phi_{2}$, (c) $\Phi_{1}$ and (d) $\Phi_{1}$.

Table 3. Relative percentage $(\mathrm{P})$ of individual forms of copper on the surface of coatings with glass microspheres after irradiation with laser pulses.

\begin{tabular}{ccccccccc}
\hline $\begin{array}{c}\text { Coatings with } \\
\text { Microspheres: }\end{array}$ & \multicolumn{2}{c}{$\mathbf{C u}$} & \multicolumn{2}{c}{$\mathbf{C u O}$} & \multicolumn{2}{c}{$\mathrm{Cu}_{\mathbf{2}} \mathbf{O}$} & \multicolumn{2}{c}{$\mathbf{C u}(\mathbf{O H})_{2}$} \\
\cline { 2 - 9 } & $\begin{array}{c}\mathbf{P} \%) \\
(\mathbf{a t} \%\end{array}$ & $\begin{array}{c}\mathbf{E}_{\mathbf{B}} \\
(\mathbf{e V})\end{array}$ & $\begin{array}{c}\mathbf{P} \\
(\mathbf{a t} \%)\end{array}$ & $\mathbf{E}_{\mathbf{B}}(\mathbf{e V})$ & $\mathbf{P}(\mathbf{a t} \%)$ & $\begin{array}{c}\mathbf{E}_{\mathbf{B}} \\
(\mathbf{e V})\end{array}$ & $\begin{array}{c}\mathbf{P} \\
(\mathbf{a t} \%)\end{array}$ & $\begin{array}{c}\mathbf{E}_{\mathbf{B}} \\
(\mathbf{e V})\end{array}$ \\
\hline$\Phi_{1}$ & 38.1 & 932.70 & 6.0 & 933.90 & 55.9 & 932.40 & - & - \\
\hline$\Phi_{2}$ & 45.1 & 932.70 & 6.7 & 933.90 & 46.2 & 932.40 & 2.0 & 934.95 \\
\hline$\Phi_{3}$ & 47.6 & 932.70 & 11.7 & 933.90 & 40.7 & 932.40 & - & - \\
\hline$\Phi_{4}$ & 49.8 & 932.70 & 13.2 & 933.90 & 37.0 & 932.40 & - & - \\
\hline
\end{tabular}


Based on the analysis of the XPS results, it was found that the copper precipitated by laser radiation occurs mainly in the form of metallic copper $(\mathrm{Cu}(0))$ and in the form of copper (I) oxide $\left(\mathrm{Cu}_{2} \mathrm{O}\right)$. These results are significantly different from those determined for coatings containing no glass microspheres, where the share of copper in the form of $\mathrm{Cu}(0)$ was less than $25 \%$ and that of metallic copper was over $30 \%$ [20]. With the increasing size of the microspheres, the percentage of copper in the form of $\mathrm{Cu}$ and $\mathrm{CuO}$ increased at the expense of the $\mathrm{Cu}_{2} \mathrm{O}$ form in laser irradiated coatings. The differences in the chemical structure may indicate different temperature conditions in the coatings irradiated with the same dose of laser, which contained microspheres of different sizes. It is generally known that the higher the temperature, the higher the degree of copper oxidation. In the case of larger glass microspheres, ablation exposed their larger surfaces, which absorbed laser radiation, heating up to higher temperatures than the polymer matrix. Therefore, the larger the diameter of the microspheres used, the more copper is detected, both in the form of $\mathrm{Cu}(0)$ and $\mathrm{CuO}$.

Laser irradiated coatings $\left(\mathrm{N}=500, \mathrm{E}_{\mathrm{th}}=100 \mathrm{~mJ} / \mathrm{cm}^{2}\right)$ underwent electroless metallization regardless of the size of the glass microspheres used. The geometric structure of the deposited copper layer reflected the geometric structure of the coating resulting from laser irradiation (Figure 10).
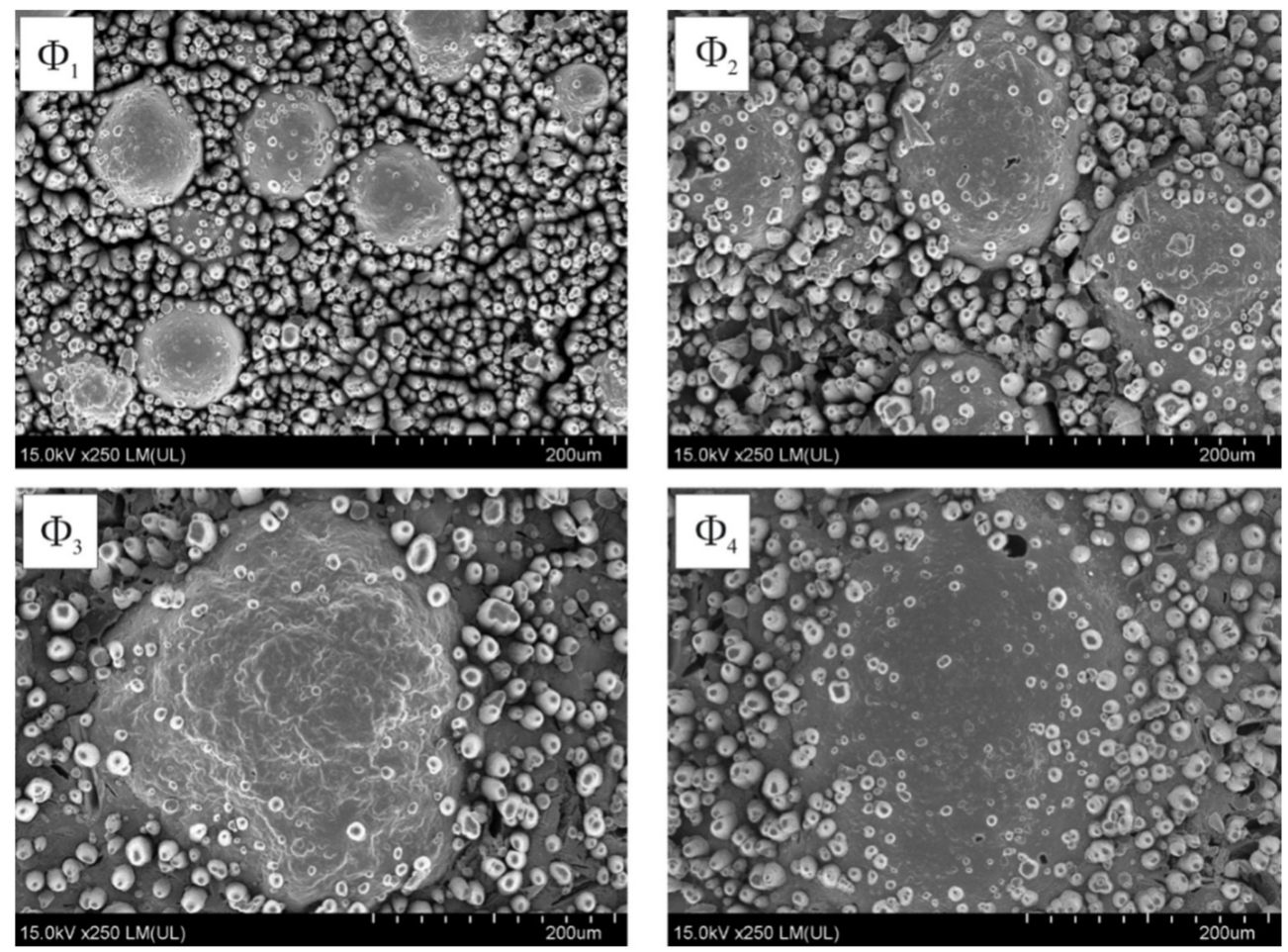

Figure 10. SEM images of laser irradiated $\left(\mathrm{N}=500 ; \mathrm{E}_{\mathrm{th}}=100 \mathrm{~mJ} / \mathrm{cm}^{2}\right)$ and electroless metallized coatings containing glass microspheres $\Phi_{1}, \Phi_{2}, \Phi_{3}$ or $\Phi_{4}$.

The EDX tests showed that the surface layer of the metallized coatings contained about 70 at $\%$ of copper, whereas the remaining proportion of oxygen and carbon atoms was in a comparable ratio of 1:2, regardless of the type of microspheres used. The EDX results for metallized coatings, however, showed significant deviation, depending on the area of the coating that was scanned. Significant local variations in the determined composition increased with the diameter of the microspheres, the size of which, especially in the case of $\Phi 4$, constituted a significant share of the scanned area.

Tests of adhesive properties were also carried out on the basis of which it was found that the adhesive strength of electroless deposited copper and polymer coating is greater than that of the polymer coating and polycarbonate substrate, because the glued stamps 
were detached with coatings from the PC substrate with registered adhesion strength of about $3 \mathrm{MPa}$. One can conclude that the adhesion strength of copper layer to polymer coatings has to exceeds this value.

\section{Conclusions}

The main aim of this study was to evaluate the effects of glass microspheres on laserinduced surface activation and electroless metallization. First of all, the presence of glass microspheres enabled reducing the content of copper(II) L-tyrosine, as a metallization precursor, to $15 \mathrm{wt} . \%$. The size of microspheres used at the same mass content was also of importance. As proved by SEM analysis, the heights of the cones formed under laser irradiation were larger for coatings containing larger size of microspheres. Moreover, more metallic copper was precipitated on surface of larger glass microspheres. However, the final metallization effect with copper was also dependent on the surface concentration of uncovered microspheres; thus, the lower the size of microspheres, the higher their concentration. Higher concentrations of uncovered microspheres resulted in the formation of continuous metallized copper layer. For that reason, the application of lower size microspheres is more preferable, especially when higher special resolution of metallized surface area is required.

Author Contributions: Conceptualization, research management, data analysis and writing (original draft preparation), P.R.; metallization of the samples, B.J.; SEM analysis, R.M.; XPS analysis, B.B.; laboratory works, K.M.; chemical synthesis of copper complex, A.W.; data analysis and corrections of the draft, P.A. All authors have read and agreed to the published version of the manuscript.

Funding: This research has been funded by the National Centre of Science granted upon decision DEC-2013/11/D/ST8/03423.

Institutional Review Board Statement: Not applicable.

Informed Consent Statement: Not applicable.

Data Availability Statement: Data is contained within the article.

Conflicts of Interest: The authors declare no conflict of interest.

Sample Availability: Samples of the copper(II) L-tyrosine are available from the authors.

\section{References}

1. Yan, Y.; Warren, S.C.; Fuller, P.; Grzybowski, B.A. Chemoelectronic circuits based on metal nanoparticles. Nat. Nanotechnol. 2016, 11, 603-608. [CrossRef] [PubMed]

2. Coiai, S.; Passaglia, E.; Pucci, A.; Ruggeri, G. Nanocomposites Based on Thermoplastic Polymers and Functional Nanofiller for Sensor Applications. Materials 2015, 8, 3377-3427. [CrossRef]

3. Augustyn, P.; Rytlewski, P.; Moraczewski, K.; Mazurkiewicz, A. A review on the direct electroplating of polymeric materials. J. Mater. Sci. 2021, 56, 14881-14899. [CrossRef]

4. Rytlewski, P.; Jagodziński, B.; Moraczewski, K. Laser-assisted Electroless Metallization of Polymer Materials: A Critical Review. Rev. Adhes. Adhes. 2016, 4, 334-366. [CrossRef]

5. Charbonnier, M.; Romand, M.; Goepfert, Y.; Léonard, D.; Bessueille, F.; Bouadi, M. Palladium (+2) reduction: A key step for the electroless Ni metallization of insulating substrates by a tin-free process. Thin Solid Film. 2006, 515, 1623-1633. [CrossRef]

6. Zhang, Y.; Hansen, H.N.; De Grave, A.; Tang, P.T.; Nielsen, J.S. Selective metallization of polymers using laser induced surface activation (LISA)—characterization and optimization of porous surface topography. Int. J. Adv. Manuf. Technol. 2011, 55, 573-580. [CrossRef]

7. Ratautas, K.; Andrulevicius, M.; Jagminienè, A.; Stankevičienè, I.; Norkus, E.; Raciukaitis, G. Laser-assisted selective copper deposition on commercial PA6 by catalytic electroless plating-Process and activation mechanism. Appl. Surf. Sci. 2019, 470, 405-410. [CrossRef]

8. Zhang, H.; Zhang, J.; Su, G.; Zhou, T.; Zhang, A. Ultraviolet photodetector on flexible polymer substrate based on nano zinc oxide and laser-induced selective metallization. Compos. Sci. Technol. 2020, 190, 108045. [CrossRef]

9. Yu, Z.; Wang, J.H.; Li, Y.; Bai, Y. Glass Fiber Reinforced Polycarbonate Composites for Laser Direct Structuring and Electroless Copper Plating. Polym. Eng. Sci. 2020, 60, 860-871. [CrossRef]

10. Amend, P.; Pscherer, C.; Rechtenwald, T.; Frick, T.; Schmidt, M. A fast and flexible method for manufacturing 3D molded interconnect devices by the use of a rapid prototyping technology. Phys. Procedia 2010, 5, 561-572. [CrossRef] 
11. Balzereita, S.; Proesb, F.; Altstädta, V.; Emmelmann, C. Properties of copper modified polyamide 12-powders and their potential for the use as laser direct structurable electronic circuit carriers. Addit. Manuf. 2018, 23, 347-354. [CrossRef]

12. Yang, J.U.; Cho, J.H.; Yoo, M.J. Selective Metallization on Copper Aluminate Composite via Laser Direct Structuring Technology. Compos. Part B Eng. 2017, 110, 361-367. [CrossRef]

13. Zhang, J.; Zhou, T.; Wen, L. Selective Metallization Induced by Laser Activation: Fabricating Metallized Patterns on Polymer via Metal Oxide Composite. ACS Appl. Mater. Interfaces 2017, 9, 8996-9005. [CrossRef]

14. Zhang, J.; Zhou, T.; Wen, L.; Zhang, A. Fabricating Metallic Circuit Patterns on Polymer Substrates through Laser and Selective Metallization. ACS Appl. Mater. Interfaces 2016, 8, 33999-34007. [CrossRef] [PubMed]

15. Geretovszky, Z.; Boyd, I. Kinetic study of $222 \mathrm{~nm}$ excimer lamp induced decomposition of palladium-acetate films. Appl. Surf. Sci. 1999, 138, 401-407. [CrossRef]

16. Charbonnier, M.; Romand, M.; Goepfert, Y. Ni direct electroless metallization of polymers by a new palladium-free process. Surf. Coat. Tech. 2006, 200, 5028-5036. [CrossRef]

17. Rytlewski, P.; Żenkiewicz, M.; Tracz, A.; Moraczewski, K.; Mróz, W. Surface morphology studies of laser irradiated and chemically metalized polyamide composites. Surf. Coat. Technol. 2011, 205, 5248-5253. [CrossRef]

18. Rytlewski, P. Laser induced electroactivity of polyamide composites. Electrochim. Acta 2012, 61, 191-197. [CrossRef]

19. Rytlewski, P.; Jagodziński, B.; Wojciechowska, A.; Moraczewski, K.; Malinowski, R. TG-FTIR coupled analysis to predetermine effective precursors for laser-activated and electroless metallized materials. J. Therm. Anal. Calorim. 2020, 141, 697-705. [CrossRef]

20. Rytlewski, P.; Jagodziński, B.; Malinowski, R.; Budner, B.; Moraczewski, K.; Wojciechowska, A.; Augustyn, P. Laser-induced surface activation and electroless metallization of polyurethane coating containing copper(II) L-tyrosine. Appl. Surf.Sci. 2020, 505, 144429. [CrossRef]

21. Wojciechowska, A.; Daszkiewicz, M.; Bieńko, A. Polymeric Zn(II) and Cu(II) complexes with exobidentate bridging l-tyrosine: Synthesis, structural and spectroscopic properties. Polyhedron 2009, 28, 1481-1489. [CrossRef]

22. Baltrusaitis, J.; Mendoza-Sanchez, B.; Fernandez, V.; Veenstra, R.; Dukstiene, N.; Roberts, A.; Fairley, N. Generalized molybdenum oxide surface chemical state XPS determination via informed amorphous sample model. Appl. Surf. Sci. 2015, 326, 151-161. [CrossRef]

23. D’Halluin, M.; Mabit, T.; Fairley, N.; Fernandez, V.; Gawande, M.B.; Le Grognec, E.; Felpin, F.-X. Graphite-supported ultra-small copper nanoparticles-Preparation, characterization and catalysis applications. Carbon 2015, 93, 974-983. [CrossRef]

24. Claeyssens, F.; Henley, S.J.; Ashfold, M.N.R. Comparison of the ablation plumes arising from ArF laser ablation of graphite, silicon, copper, and aluminum in vacuum. J. Appl. Phys. 2003, 94, 2203. [CrossRef]

25. Dyer, P. Excimer laser polymer ablation: Twenty years on. Appl. Phys. A 2003, 77, 16. [CrossRef] 